\title{
PENGEMBANGAN EKOWISATA AIR TERJUN SINGSING SADE, DI DESA BELIMBING, KECAMATAN PUPUAN, KABUPATEN TABANAN
}

\author{
N.L.R. Purnawan ${ }^{1}$, I D.P. Singarsa ${ }^{2}$, I K. Sardiana ${ }^{2}$
}

\begin{abstract}
ABSTRAK
Tujuan KKN PPM di Desa Belimbing, Kecamatan Pupuan Kabupaten Tabanan adalah untuk pemberdayaan kelompok sadar wisata (POKDARWIS) dalam mengembangkan potensi ekowisata dengan Air Terjun Singsing Sade sebagai point of interest utama. Metode yang ditempuh untuk mencapai tujuan tersebut adalah melalui pendidikan, pelatihan, simulasi Ipteks, dan pendampingan. Pendekatan yang digunakan meliputi: transfer tenologi tepat guna kepada masyarakat, pengembangan wawasan kewirausahaan, dan pemanfaatan IT (e-commerce untuk menjalin kemitraan pemasaran). Kegiatan yang telah dilaksanakan diantaranya: pengembangan Singsing Sade sebagai paket ekowisata, perbaikan kelembagaan dan SDM POKDARWIS, penyediaan sarana penunjang paket ekowisata, pengembangan kemitraan pemasaran dan promosi paket ekowisata.
\end{abstract}

Kata Kunci : kuliah kerja nyata, pengembangan, ekowisata, air terjun Singsing Sade

\begin{abstract}
The purpose of KKN PPM in Belimbing Village, Pupuan Sub-district of Tabanan District is to empower the tourism conscious group (POKDARWIS) in developing Singsing Sade waterfall as an ecotourism tourist attraction. Methods of delivery include training and education, simulation, mentoring and technology transfer. The approaches used include: (1) transfer of knowledge to the community, entrepreneurship capacity building, and utilization of information technology (e-commerce). Result indicated that the following activities have been successfully conducted, such as : sharing experiences on ecotourism development potential; workshop and focus group discussion on ecotourism package of Sing-sing sade; Administrative training, AD / ART compilation and programs, and computer training for website operations for tourism conscious groups (POKDARWIS); English language training, guiding techniques and yoga instructor / ecological tour Sing-Sing Sade; Creating trekking track maps to Sing-Sing Sade, brochures, and websites for promotion and marketing of Sing-sing sade ecological tourism packages;
\end{abstract}

Keywords : Kuliah Kerja Nyata ( campus community engagement), development, ecotourism, Singsing Sade Waterfall

\footnotetext{
${ }^{1}$ Staf Pengajar FISIP Universitas Udayana, ramaswati.purnawan@unud.ac.id

${ }^{2}$ Staf Pengajar Program Studi Agroekoteknologi,Fakultas Pertanian Universitas Udayana,
} 


\section{PENDAHULUAN}

Kecamatan Pupuan terletak di bagian barat Kabupaten Tabanan, sebagian besar wilayahnya berupa perbukitan, dengan tebing-tebing curam dan menjadi hulu dari beberapa sungai yang mengalir di Kabupaten Tabanan. Desa Belimbing telah ditetapkan sebagai salah satu Desa Wisata di Kabupaten Tabanan. Salah satu daya tarik pariwisata unggulan yang terdapat di Desa Belimbing adalah air terjun yang disebut "Singsing Sade".

Air terjun Singsing Sade bermakna air terjun kembar yang menyatu menjadi satu di sebuah hulu sungai. Secara mitologis air terjun ini diyakini sebagai air terjun yang bertuah sebagai pemersatu bagi pasangan suami istri yang sedang mengalami percekcokan. Oleh sebab itu, banyak pasangan yang sedang menghadapi permasalahan dalam rumah tangga datang lokasi ini. Lokasi air terjun ini yang terletak di hutan yang masih lestari dengan suasana hening didukung oleh udara pegunungan yang sejuk menjadikan tempat menarik minat wisatawan untuk kegiatan ekowisata. Namun demikian, potensi daya tarik air terjun Singsing Sade sebagai obyek ekowisata yang begitu besar ternyata belum dikelola secara memadai. Pada hal apabila daya tarik wisata ini dikembangkan dan dikemas menjadi paket wisata yang sesuai standar akan dapat sebagai sumber pendapatan bagi masyarakat.

Persoalan yang dihadapi dalam pengembangan potensi pariwisata air terjun Singsing Sade di Kecamatan Pupuan diantaranya : potensi yang belum dikemas maksimal, kelompok masyarakat sadar wisata (Pokdarwis) belum berjalan produktif dalam mengelola dan mengembangkan potensi yang ada, ketrampilan dan kemampuan SDM yang perlu ditingkatkan terkait manajemen dan pelayanan dan pengembangan jaringan pemasaran paket wisata
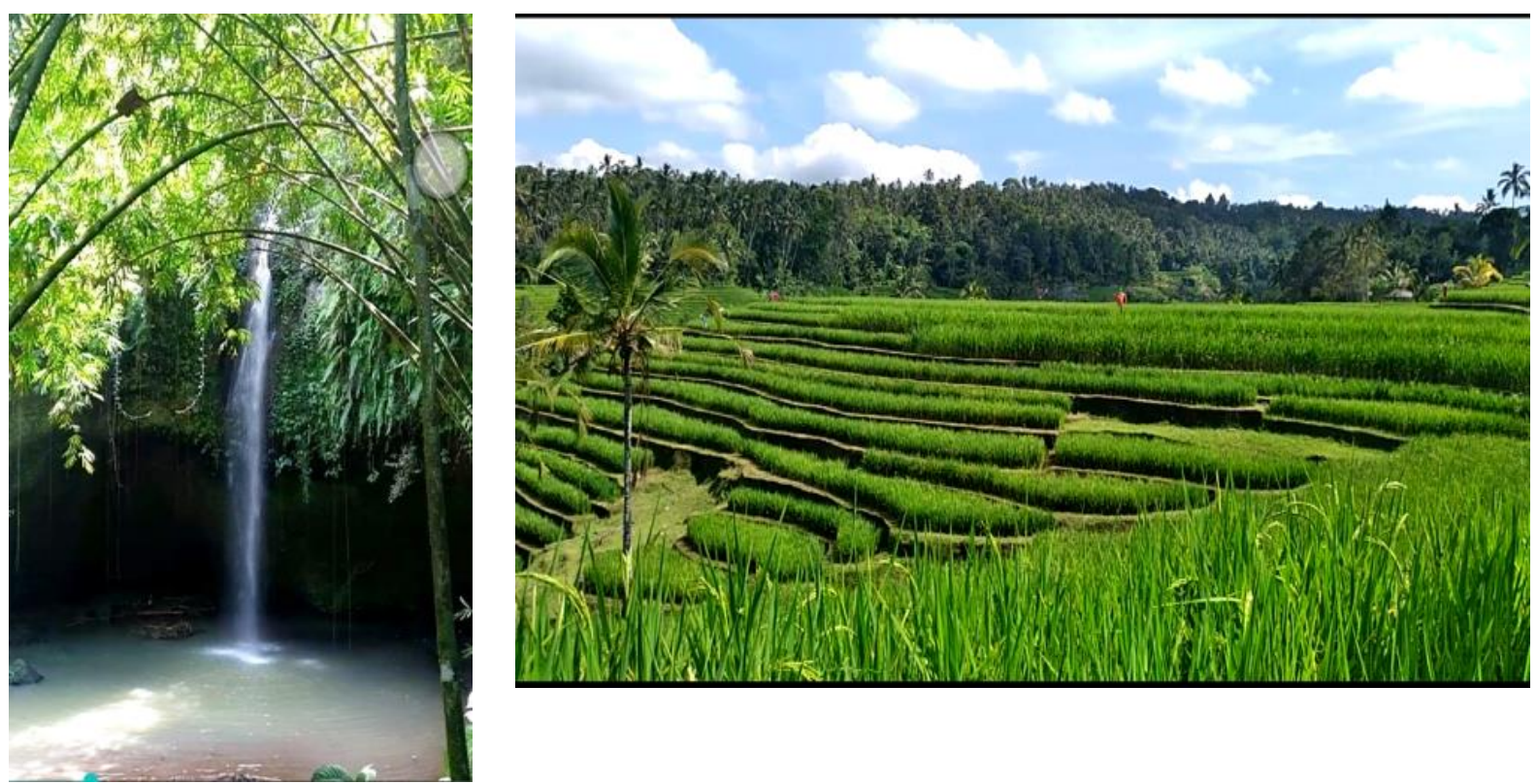

Gambar 1. Potensi air terjun Singsing Sade dan sekitarnya Foto : Ramaswati Purnawan, 2017 


\section{METODE PELAKSANAAN}

Metode yang diterapkan dalam kegiatan KKN PPM ini meliputi: Kordinasi, pelathan, penyuluhan dan berbagi pengalaman tetang potensi pengembangan ekowisata, sarasehan dan FGD penyusunan paket ekowisata Singsing Sade.

Metode yang ditempuh untuk mencapai tujuan tersebut adalah melalui pendidikan, pelatihan, simulasi Ipteks, dan pendampingan. Pendekatan yang digunakan meliputi: (1) transfer tenologi tepat guna kepada masyarakat (2) Pengembangan wawasan kewirausahaan, dan (3) pemanfaatan IT (e-commerce untuk menjalin kemitraan pemasaran).

\section{HASIL DAN PEMBAHASAN}

Kegiatan yang telah diakukan pada program KKN PPM di Desa Belimbing meliputi kegiatan berikut ini :

1. Penataan Jalur Trekking, meliputi pembuatan jalan tangga dan penanaman pohon sepanjang jalur trekking

2. Penyusunan paket ekowisata, berkoordinasi dengan kelompok sadar wisata (Pokdarwis) Desa Belimbing, menghasilkan paket ekowisata dan peta trekking

3. Penyuluhan dan Pelatihan Pengembangan Ekowisata, meliputi : pengembangan potensi wilayah; penguatan manajemen Pokdarwis dan Pelayanan Prima; Pelatihan Guiding dan Bahasa Inggris.termasuk edukasi Sapta Pesona. Selain itu kegiatan ini juga diikuti dengan penyerahan peralatan penunjang wisata

4. Pengembangan/promosi paket desa ekowisata, berupa brosur dan website

\section{KESIMPULAN DAN SARAN}

Kesimpulan

1. Pengembangan desa wisata melalui pengembangan paket ekowisata mendapat sambutan positif dari masyarakat.

2. Pengembangan Desa Wisata merupakan alternative kepariwisataan Bali yang potensial untuk dikembangkan sebagai upaya peningkatan kesejahteraan hidup masyarakat setempat

Saran

1. Diperlukan pelatihan dan pendampingan lebih lanjut dan terintegrasi antara pemerintah, akademisi dan industri pariwisata agar pengelolaan Desa Wisata dapat dilakukan secara mandiri oleh masyarakat Desa Belimbing sehingga tujuan untuk meningkatkan kesejahteraan masyarakat dapat tercapai.

\section{UCAPAN TERIMA KASIH}

Ucapan terimakasih yang sebesar-besarnya kami sampaikan kepada berbagai pihak yang telah membantu pelaksanaan kegiatan KKN PPM ini, yakni DRPM Kemenristek Dikti atas bantuan dana kegiatan; Universitas Udayana melalui kegiatan KKN PPM; Pemda Kabupaten Tabanan, beserta aparat Desa, Pokdarwis dan masyarakat Desa Belimbing; serta mahasiswa KKN Belimbing 2017, sehingga kegiatan KKN PPM ini dapat terlaksana dengan baik. 


\section{DAFTAR PUSTAKA}

Kementerian Pariwisata dan Ekonomi Kreatif (2012) Pedoman Kelompok Sadar Wisata. Jakarta

McLeod, N (2006) 'Cultural Tourism : Aspects of Authenticity and Commodifiction' in Smith, MK and Robinson, M (eds) Cultural Tourism in a Changing World : Politics, Participation and (Re)presentation

Pitana, I Gde dan Surya Diarta, I Ketut (2009) Pengantar Ilmu Pariwisata. Yogyakarta : Penerbit ANDI

Vickers, Andrian (1989) Bali: A Paradise Created. Hongkong: Periplus

www.kemenpar.go.id 